\title{
The Application of SMC Model to Measurement of Customer Equity Purchasing Value in B2B Market
}

\author{
Ai-Wu Cheng \\ Xi'an Polytechnic University \\ E-Mail: Cheng1955@126.com \\ $\mathrm{Xi}-\mathrm{Chan} \mathrm{Mu}$ \\ Shaanxi Weide Technology Corporation \\ E-Mail: xichanmu@yahoo.com \\ Lin Sun \\ Xi'an Polytechnic University \\ E-Mail: 348428012@qq.com \\ Fan $\mathrm{Yu}$ \\ Xi'an Polytechnic University \\ E-Mail: canvasfan@gmail.com
}

\begin{abstract}
The article analyzes the adaptability of SMC model, based on the features of purchase decision in B2B market. At the beginning of this article, we introduce the SMC model and its hypothesis, and then modify the model considering the characteristics of $\mathrm{B} 2 \mathrm{~B}$ market and the effects on purchasing decisions from the services provided by suppliers. Finally, we examine the modified model by a case, and compare the forecast results of the unmodified model with those of the modified model. The result proves that the modified model is more accurate and more scientific than the general SMC model on predicting the customer equity purchasing value in B2B market. Additionally, it also testifies the comprehensive adaptability of SMC model which must consider the adjustment of parameter calculation on the basis of the characters of purchasing behaviors.
\end{abstract}

Keywords: SMC Model, B2B Market, Customer Equity, Potential Purchasing Value 


\section{FOREWORD}

Customer equity is the total profits of doing business with the loyal customers in customer life cycle, in which the most important value comes from purchasing. Therefore, quantitative analysis is used in the research of customer equity measurement, and then scholars construct the metrological model according to the laws of the development of customer purchasing value, such as Dwyer's customer transfer model (Dwyer, 1989), CLV forecasting method of customer classification in industrial market of Jackson (1985), Pareto/NBD model (Pfeifer and Carraway, 2000) and SMC model, and so on. These models discuss the quantitative evaluation of customer equity from different angles, laying the foundation of evaluating the intangible assets of customer equity. At the same time, it also promotes the effective use of this vital resource and the scientific management. Among these models, SMC model attracts more and more attentions for predicting customers' future purchasing behaviors according to their historical records, and the effective use of client database and reflecting the strengths of customer actual purchasing value objectively. Especially under the support of data mining technology, the strengths are more visible. But, in the present literatures, it lacks corresponding analysis of the differences in buying behaviors in different industries that influence the accuracy and applicability of model. Based on the above, the article regards customer purchasing behaviors in B2B market as the object, and studies future customer equity purchasing value using SMC model. We hope it will be more fully in reflecting the characteristics of B2B markets and increase forecasting accuracy by our improving the model. At the beginning of this article, we introduce the SMC model and its hypothesis, and then modify the model considering the characteristics of B2B market and the effects on purchasing decisions from the services provided by suppliers. Finally, an example is given to show that the modified model is more suitable to analyze customer purchasing behaviors in $\mathrm{B} 2 \mathrm{~B}$ market.

\section{BRIEF INTRODUCTION OF SMC MODEL}

In 1987, David C Schmittlein, Donald G Morrison, Richard Colombo put forward SMC model (1987), then perfected by David C Schmittlein and Robert A Peterson in 1994. It's a method of analyzing customer future buying behaviors according to their historical records, called SMC for short. Its specific content is to construct a group of models describing random individual customer buying behaviors by using the frequency and other information. And then make a prediction in the light of customer activity, expected purchasing frequency and the possibility of buying. The 
preconditions of SMC model are as follows: (1)the random purchasing process of active customers yields to Poisson distribution. (2)the life time of individual customer keeps to exponential distribution. (3)there is a huge variation of customer buying rate depicted by $\Gamma$ distribution. (4)heterogeneity exists in customer attrition rate which keeps to $\Gamma$ distribution. (5) the customer purchasing rate $\lambda$ is independent of customer attrition rate $\mu$. By the hypotheses above, SMC model includes the following models:

(1) The activity model of individual customer at the time of T:

$$
P[\tau>T \mid r, \alpha, s, \beta, X=x, t, T]=\int_{0}^{\infty} \int_{0}^{\infty} P[\tau>T \mid \lambda, \mu, X=x, t, T] f(\lambda, \mu \mid r, \alpha, s, \beta, X=x, t, T) d_{\lambda} d_{\mu}
$$

This model shows variations according to parameters $\alpha, \beta$

(2) The probabilistic model of customer doing $x^{*}$ business deals in the period of $t^{*}$ after the time of $\mathrm{T}$ :

$$
\begin{aligned}
& P\left[X^{*}=x^{*} \mid r, s, \alpha, \beta, X=x, t, T, t^{*}\right] \\
= & P[\tau>T \mid r, s, \alpha, \beta, X=x, t, T] * P\left[X^{*}=x^{*} \mid r, s, \alpha, \beta, X=x, t, T, t^{*}\right]
\end{aligned}
$$

(3) The expectancy model of customer purchasing frequency in the period of $t^{*}$ after the time $\mathrm{T}$

$$
E\left[X^{*}=x^{*} \mid r, s, \alpha, \beta, X=x, t, T, t^{*}\right]=P[\tau>T \mid r, s, \alpha, \beta, X=x, t, T] * E\left[r^{*}, s^{*}, \alpha^{*}, \beta^{*}, t^{*}\right]
$$

(4) The expectancy model of customers' each volume of business

Here are some preconditions of this model: (1) $Z_{i}$ means a customer's each volume of business, $i=1,2, \cdots, x$ is the variable of normal distribution, the average value is $\theta$, the variance is $\sigma_{W}^{2}$, (2) the historical average volume of business of all customers yield to normal distribution, the expected value is $E(\theta)$, the variance is $\sigma_{A}^{2}$, (3) the historical average volume of business of individual customer $\theta$ and the purchasing rate $\lambda$ and the attrition rate $\mu$ are independent of each other. If customer purchasing records are different, so are the dependent coefficient and the next purchasing expected value. When the record is 1 , the expected value of volume of business again is

$$
E\left[\theta \mid Z_{1}\right]=\rho_{1} Z_{1}+\left(1-\rho_{1}\right) E[\theta]
$$


When the record is above 1 , the expected value of volume of business again is:

$$
\begin{aligned}
& E\left[\theta \mid Z_{1}, Z_{2}, \cdots, Z_{x}\right]=\rho_{x} \bar{Z}+\left(1-\rho_{x}\right) E[\theta] \\
& =\left(\frac{X \sigma_{A}^{2}}{X \sigma_{A}^{2}+\sigma_{W}^{2}}\right) \bar{Z}+\left(\frac{\sigma_{A}^{2}}{X \sigma_{A}^{2}+\sigma_{W}^{2}}\right) E[\theta]
\end{aligned}
$$

Under the above hypothesis, the total volume of business of a customer in the future period of $t^{*}$ is related to the trading times and each trading volume during the period, the product of these two variables:

$$
E\left[Z \mid X, t^{*}\right]=E\left[Z \mid Z_{1}, Z_{2}, \cdots, Z_{x}\right] \times E\left[x^{*} \mid X, t^{*}\right]
$$

$E\left(Z \mid X, t^{*}\right)$ means the expected value of the volume of business in the period of $t^{*}$ after the time $t_{2}$ according to the historical trading information of $X=(x, t, T)$, $E\left[Z \mid Z_{1}, Z_{2}, \cdots, Z_{x}\right]$ means the expected value of the future volume of business predicted by the pervious $x$ times historical trading volume, $E\left[x^{*} \mid X, t^{*}\right\rfloor$ indicates the expected value of trading times in the period of $t^{*}$ after the time T.

\section{THE MODIFICATION OF SMC MODEL}

\section{The Analysis of the Impact on Customer Purchasing in Industrial Market Produced by Service}

With the development of science, the importance of service in B2B market can greatly influence purchasing behavior. The service can be demonstrated into two aspects: one is supportive service, including warranties for goods, supply and service of parts, the assistance and training of users; the others are feedback and compensation, including settlement of complaint and disputes, refund and so on. High quality service has positive effects on increasing the efficiency, reducing the expense of employees' training and improving the quality of products. For these reasons, customers in B2B market attach great importance to the service; they even stop the cooperation with suppliers with an attractive price when they are dissatisfied with the service. In turn, the service is also one of the competitive strengths of companies which should be produced. Some companies attract potential customers and also enhance the potential purchasing value of current customers at the same time by providing unique service.

According to these analyses, we conclude that we must consider the effect of service on customer buying decision when we predict the customer equity purchasing 
value in B2B market. But previously, we didn't regard the service as a significant element when using the SMC model to analyze the buying behaviors in B2B market; as a result, we can't get objective and accurate results from the prediction of customer equity purchasing value, which has a negative impact on marketing decision. So, it occurs to be necessary and significant to modify SMC model according to the characters of customer purchasing in B2B market.

\section{The Basic Hypothesis of Model Parameter}

According to the features of customer buying decision in industrial market and the related literatures, we give complementary hypotheses as follows:

(6)the suppliers' service is a key factor of customer equity purchasing value.

(7)the service is positive correlated with customer purchasing rate.

(8)Based on the results of comparing the expecting service ( $\left.S_{\text {anticipating }}\right)$ and the actual service ( $S_{\text {act ual }}$ ), there are two states of service: when $S_{\text {ant i ci pat i ng }}>S_{\text {act ual }}$, customers are dissatisfied with the service; when $S_{\text {ant ici pat ing }} \leq S_{\text {act ual }}$, customers are satisfied with the service. Suppose the rate of customers' satisfaction with the actual service is $p$ in each trading process, and the rate of dissatisfaction is $1-p$.

(9) One customer only transacts with a supplier per unit time, each trading volume obeys a random distribution, and the expected value is $\mathrm{Q}$.

\section{Make up Model without Considering Customers' Eterogeneity}

According to hypothesis (1), the rate of customer transaction yields to Poisson distribution, its purchasing transferring process is a continuous Markov chain. Now we suppose that in industrial market, the rate of customer transaction is only related to the last service, when customers are dissatisfied with the service, the next rate of transaction is $\lambda_{1}$; when customers are satisfied with the service, the next rate of transaction is $\lambda_{2}$, and $\lambda_{1}<\lambda_{2}$, namely

$$
P[N=n \mid \lambda, t]=\frac{(\lambda t)^{n}}{n !} e^{-\lambda t}, t>0, \lambda_{1}, \lambda_{2}-\text { rate of customer transaction }
$$

According to the hypotheses (8), services have two conditions, one is the customers' dissatisfaction with the services, another is the customers' satisfaction with the services. Now the beginning time is ${ }^{t=0}, T$ is a customer's life cycle, according to Markov chain (Lin, 2002) $\lambda_{2}>\lambda_{1}$, the transition probability matrix is as following: 


$$
P=\left(P_{i j}\right)=\left(\begin{array}{cc}
(1-p) \frac{\lambda_{1}}{\lambda_{2}}+\left(1-\frac{\lambda_{1}}{\lambda_{2}}\right. & p \frac{\lambda_{1}}{\lambda_{2}} \\
1-p & p
\end{array}\right)=\left(\begin{array}{cc}
1-p \frac{\lambda_{1}}{\lambda_{2}} & p \frac{\lambda_{1}}{\lambda_{2}} \\
1-p & p
\end{array}\right)
$$

$N_{j}^{i}(n)$ stands for the random expectation value of $\mathrm{n}$ times transfer from state $i$ to state $j, i, j \in\{1,2\}$. So through a series of recursive, and make $W=\left(\begin{array}{cc}0 & 0 \\ (1-p) / p & 1\end{array}\right)$, $N(0)=0, N(1)=P W$

We can get that: $N(n)=\left(\sum_{k=1}^{n} p^{k}\right) W$

(1) $t=0$, customers are dissatisfied with the suppliers' service in transaction process

$$
N_{1}^{1}(n)+N_{2}^{1}(n)=\frac{\lambda_{1}}{\lambda} n-\frac{\lambda_{1} \lambda_{2}}{\lambda^{2}} \alpha_{2}+\frac{\lambda_{1} \lambda_{2}}{\lambda^{2}} \alpha_{2}^{n+1}
$$

Because customer transaction keeps to random Poisson distribution, and individual customer's survival time keeps to Exponential distribution, times of anticipating purchase of customers

$$
\frac{\lambda_{1} \lambda_{2}}{\lambda \mu}\left(1-e^{\mu t}\right)-\frac{p \lambda_{1}\left(\lambda_{2}-\lambda_{1}\right)}{\lambda(\lambda+\mu)}\left(1-e^{-(\lambda+\mu) t}\right)
$$

Anticipating purchase of customers among $(0, T]$

$$
M_{1}=Q\left[\frac{\lambda_{1} \lambda_{2}}{\lambda \mu}\left(1-e^{\mu T}\right)-\frac{p \lambda_{1}\left(\lambda_{2}-\lambda_{1}\right)}{\lambda(\lambda+\mu)}\left(1-e^{-(\lambda+\mu) T}\right)\right]
$$

(2)when $t=0$ ' customers are satisfied with the suppliers' service in transaction process, similarly there is

$$
N_{1}^{1}(n)+N_{2}^{1}(n)=\frac{\lambda_{1}}{\lambda} n+\frac{(1-p) \lambda_{2}^{2}}{p \lambda^{2}} \alpha_{2}-\frac{(1-p) \lambda_{2}^{2}}{p \lambda^{2}} \alpha_{2}^{n+1}
$$

Times of anticipating purchase of customers

$$
\frac{\lambda_{1} \lambda_{2}}{\lambda \mu}\left(1-e^{\mu T}\right)+\frac{(1-p) \lambda_{2}\left(\lambda_{2}-\lambda_{1}\right)}{\lambda(\lambda+\mu)}\left(1-e^{-(\lambda+\mu) T}\right)
$$


Quantity of anticipating purchase of customers among $(0, T]$

$$
M_{2}=Q\left[\frac{\lambda_{1} \lambda_{2}}{\lambda \mu}\left(1-e^{\mu T}\right)+\frac{(1-p) \lambda_{2}\left(\lambda_{2}-\lambda_{1}\right)}{\lambda(\lambda+\mu)}\left(1-e^{-(\lambda+\mu) T}\right)\right]
$$

Total quantity of anticipating purchase

$$
M=(1-p) M_{1}+p M_{2}=Q\left[\frac{\lambda_{1} \lambda_{2}}{\lambda \mu}\left(1-e^{\mu T}\right)+\frac{p(1-p)\left(\lambda_{2}-\lambda_{1}\right)^{2}}{\lambda(\lambda+\mu)}\left(1-e^{-(\lambda+\mu) T}\right)\right]
$$

By (7) and (9), $M_{2}-M_{1}>0$, that's to say, when customers are satisfied with the suppliers' service in transaction process, they will buy more products.

\section{Make up Model by Considering Customers' Heterogeneity}

In view of the heterogeneity of customers purchase rate and wastage rate, we can take it that when $\lambda_{1}$ is high, $\lambda_{2}$ should also be high. In other words, there is a certain interaction between $\lambda_{1}$ and $\lambda_{2}$. For the sake of convenience, we form a hypothesis that if $\lambda_{1}=k \lambda_{2}(0<k<1), \lambda=[1+(k-1) p] \lambda_{2}$, then make $p_{k}=1+(k-1) p$, namely $\lambda=p_{k} \lambda_{2} \quad(k$ is coefficient, indicating the degree of the heterogeneity of customer purchase rate). $t=0$, customers are dissatisfied with the suppliers' service

$$
M_{1}=Q \int_{0}^{\infty} \int_{0}^{\infty}\left[\frac{k \lambda_{2}}{p_{k} \mu}\left(1-e^{\mu T}\right)-\frac{p k \lambda_{2}(1-k)}{p_{k}\left(p_{k} \lambda_{2}+\mu\right)}\left(1-e^{-(\lambda+\mu) T}\right)\right] \times g\left(\lambda_{2} \mid r, \alpha\right) \times h(\mu \mid s, \beta) d_{\lambda_{2}} d_{\mu}
$$

When $p_{k}=\frac{\alpha}{\beta}$

$$
M_{1}=Q\left\{\left[\frac{k r \beta}{p_{k} \alpha(s-1)}\left(1-\left(\frac{\beta}{\beta+T}\right)^{s-1}\right)\right]-\frac{p k(1-k) \alpha^{r} \beta^{s} r}{p_{k}^{r+2}(r+s)}\left[\frac{1}{\beta^{r+s}}-\frac{1}{(\beta+T)^{r+s}}\right]\right\}
$$

When $p_{k} \neq \frac{\alpha}{\beta}$

$$
M_{1}=Q\left\{\left[\frac{k r \beta}{p_{k} \alpha(s-1)}\left(1-\left(\frac{\beta}{\beta+T}\right)^{s-1}\right)\right]-\frac{p k(1-k) \alpha^{r} \beta^{s} r}{p_{k}^{r+2}(r+s)}\left[\frac{F\left(a, b, c, z_{1}\right)}{\beta^{r+s}}-\frac{F\left(a, b . c \cdot z_{2}\right)}{(\beta+T)^{r+s}}\right]\right\}
$$


(2) when $t=0$, customers are satisfied with the suppliers' service

$$
M_{2}=Q \int_{0}^{\infty} \int_{0}^{\infty}\left[\frac{k \lambda_{2}}{p_{k} \mu}\left(1-e^{\mu T}\right)+\frac{(1-p) \lambda_{2}(1-k)}{p_{k}\left(p_{k} \lambda_{2}+\mu\right)}\left(1-e^{-\left(p_{2} \lambda_{k}+\mu\right) T}\right)\right] \times g\left(\lambda_{2} \mid r, \alpha\right) \times h(\mu \mid s, \beta) d_{\lambda_{2}} d_{\mu}
$$

When $p_{k}=\frac{\alpha}{\beta}$

$$
M_{2}=Q\left\{\left[\frac{k r \beta}{p_{k} \alpha(s-1)}\left(1-\left(\frac{\beta}{\beta+T}\right)^{s-1}\right)\right]+\frac{(1-p)(1-k) \alpha^{r} \beta^{s} r}{p_{k}^{r+2}(r+s)}\left[\frac{1}{\beta^{r+s}}-\frac{1}{(\beta+T)^{r+s}}\right]\right\}
$$

When

$$
\begin{aligned}
& p_{k} \neq \frac{\alpha}{\beta} \\
& M_{2}=Q\left\{\left[\frac{k r \beta}{p_{k} \alpha(s-1)}\left(1-\left(\frac{\beta}{\beta+T}\right)^{s-1}\right)\right]+\frac{(1-p)(1-k) \alpha^{r} \beta^{s} r}{p_{k}^{r+2}(r+s)}\left[\frac{F\left(a, b, c, z_{1}\right)}{\beta^{r+s}}-\frac{F\left(a, b \cdot c \cdot z_{2}\right)}{(\beta+T)^{r+s}}\right]\right\}
\end{aligned}
$$

\section{EMPIRICAL ANALYSIS}

A is a large enterprise, mainly producing metallurgical installation and mining machine. It is the leader in the industry, which has an annual turnover of about a billion. This enterprise doesn't have many customers, most of whom are steel mills, coal mine enterprises or research institutes. The company has a close relationship with customers and can keep a long correlation, which is characterized by the classic features of industrial market. We build a prediction model by taking data of customers' transaction from July 2006 to July 2008 as the firsthand information, taking the data of the first 23 months as the experiment set and the data of the 24 month as the test set. By comparing the prediction data and text data, we testify the modified SMC model. We selected 556 customers randomly whose initial trade occurred after July 1st, 2006 .All the samples are divided into sample customers I and sample customers II, the first is the experiment group and the second is the test group. During the process, we selected 8 customers from sample I randomly. Firstly, we get customer activity and customer anticipating transaction by using the general SMC model, then, we use the formula:

potential purchasing value of customer equity $=$ customer anticipating transaction $\times$ customer activity 
it is found that the potential purchasing value of the 8 customers in the 24 month; Then, calculate the potential purchasing value of the 8 customers in the 24 month by the modified SMC model. See Table 1.

Table 1 Potential purchasing value of customer equity

\begin{tabular}{cccccc}
\hline $\begin{array}{c}\text { Customer } \\
\text { number }\end{array}$ & $\begin{array}{c}\text { Probability of } \\
\text { anticipating } \\
\text { activity }\end{array}$ & $\begin{array}{c}\text { Quantity of } \\
\text { anticipating } \\
\text { transaction }\end{array}$ & $\begin{array}{c}\text { Potential } \\
\text { purchasing } \\
\text { value of } \\
\text { customer } \\
\text { equity }\end{array}$ & $\begin{array}{c}\text { Modified } \\
\text { quantity of } \\
\text { anticipating } \\
\text { transaction }\end{array}$ & $\begin{array}{c}\text { Modified } \\
\text { potential } \\
\text { purchasing } \\
\text { value of } \\
\text { customer equity }\end{array}$ \\
\hline 1 & 0.021 & 191.442 & 4.020 & 194.541 & 4.085 \\
\hline 2 & 0.928 & 220.093 & 204.246 & 223.192 & 207.123 \\
\hline 3 & 0.882 & 83.867 & 73.971 & 84.643 & 74.655 \\
\hline 4 & 0.966 & 226.687 & 218.980 & 229.786 & 221.973 \\
\hline 5 & 0.927 & 27.994 & 25.950 & 28.098 & 26.047 \\
\hline 6 & 0.767 & 246.240 & 188.866 & 249.984 & 191.738 \\
\hline 7 & 0.867 & 215.920 & 187.203 & 219.019 & 189.890 \\
\hline 8 & 0.579 & 196.404 & 113.718 & 199.503 & 115.512 \\
\hline
\end{tabular}

Finally, we compare the modified and unmodified predicted value of customer potential purchasing value with the actual value. In the table, ${ }_{i}$ means customer actual purchasing value on July, 2008, and $\hat{Z}_{i}$ is the predicted value on the same period. The results of error analysis and comparison are shown in Table 2.

Table2 The error analysis table

\begin{tabular}{cccccc}
\hline \multirow{2}{*}{$\begin{array}{c}\text { Customer } \\
\text { number }\end{array}$} & $Z_{i}$ & \multicolumn{2}{c}{$\hat{Z}_{i}$} & \multicolumn{2}{c}{$\varepsilon$} \\
\cline { 3 - 6 } & & $\begin{array}{c}\text { Before } \\
\text { modify }\end{array}$ & After modify & $\begin{array}{c}\text { Before } \\
\text { modify }\end{array}$ & After modify \\
\hline 1 & 4.149 & 4.020 & 4.085 & $3.11 \%$ & $1.54 \%$ \\
\hline 2 & 208.440 & 204.246 & 207.123 & $2.01 \%$ & $0.63 \%$ \\
\hline 3 & 76.030 & 73.971 & 74.655 & $0.99 \%$ & $0.36 \%$ \\
\hline 4 & 225.163 & 218.980 & 221.973 & $2.75 \%$ & $1.42 \%$ \\
\hline 5 & 26.938 & 25.950 & 26.047 & $3.67 \%$ & $3.31 \%$ \\
\hline 6 & 195.916 & 188.866 & 191.738 & $3.40 \%$ & $2.13 \%$ \\
\hline 7 & 190.700 & 187.203 & 189.890 & $1.83 \%$ & $0.42 \%$ \\
\hline 8 & 118.950 & 113.718 & 115.512 & $4.40 \%$ & $2.89 \%$ \\
\hline Total & 1046.286 & 1016.954 & 1031.023 & $2.88 \%$ & $1.46 \%$ \\
\hline
\end{tabular}


It can be seen from Table 3 that unmodified total error is $2.88 \%$, the maximum predicted error is $4.40 \%$; modified total error is $1.46 \%$, the maximum predicted error is $3.31 \%$. This proves that the accuracy and effectiveness of predicting purchasing value of customer equity have been improved significantly after modifying SMC model based on the features of buying decision of B2B market.

\section{CONCLUSIONS}

Through discussing the effects of suppliers' service on customer purchasing decision behavior in B2B market, we provide a modified SMC model and use it to predict the purchasing value of customers' equity. By testing the modified model with practical data, it proves that modified SMC model is more scientific and accurate than general SMC model in terms of purchasing value of customer equity in B2B market. The conclusion of this paper also proves that SMC model has a wide range of application, but parameter calculation has to be adjusted based on the features of the object's purchase behavior. However, this study is only an abecedarian research. We simply consider the effect of service on customer purchase decision in B2B market and make no analysis of any other marketing variables that remain to be researched to make SMC model much more accurate and detailed in predicting purchasing value of customer equity.

\section{ACKNOWLEDGEMENTS}

Fund project: The National Natural Science Fund (70672116)

\section{REFERENCES}

Dwyer, F. Robert (1989). Customer Lifetime Valuation to Support Marketing Decision Making. Journal of Direct Marketing, 3(4), 8-15.

Jackson, B. B. (1985). Winning and Keeping Industrial Customers. Lexington, MA: D. C. Heath and Company, 132-145.

Lin, Y. 1. (2002). Stochastic process. Beijing: Tsing-hua University Press, 78-119.

Pfeifer, P. E. and Carraway, R. L. (2000). Modeling Customer Relationships as Markov Chains. Journal of Interactive Marketing, 14(2), 43-55.

Schmittlein, D. C., Morrison, D. G., and Colombo R. (1987). Counting Your Customers: Who Are they and What Will They Do next? Management Science, 33(1), 1-24.

Schmittlein, David C. and Peterson, Robert A. (1994). Customer base analysis: an industrial purchase processes process application. Marketing Science, 13(1), 41-67. 